\title{
The Development of Radioactive Sample Surrogates for Training and Exercises
}

\section{Methods in Radioanalytical Chemistry IX}

Kevin Carney

Martha Finck

Christopher McGrath

Bevin Brush

Dick Jansen

Donald Dry

George Brooks

David Chamberlain

The INL is a

U.S. Department of Energy

National Laboratory

operated by

Battelle Energy Alliance

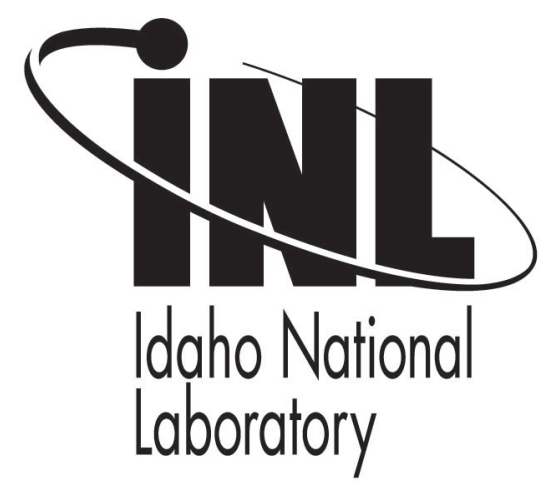

\section{March 2012}

This is a preprint of a paper intended for publication in a journal or proceedings. Since changes may be made before publication, this preprint should not be cited or reproduced without permission of the author. This document was prepared as an account of work sponsored by an agency of the United States Government. Neither the United States Government nor any agency thereof, or any of their employees, makes any warranty, expressed or implied, or assumes any legal liability or responsibility for any third party's use, or the results of such use, of any information, apparatus, product or process disclosed in this report, or represents that its use by such third party would not infringe privately owned rights. The views expressed in this paper are not necessarily those of the United States Government or the sponsoring agency. 


\title{
The development of radioactive sample surrogates for training and exercises
}

\author{
Kevin Carney $\cdot$ Martha Finck $\cdot$ Christopher McGrath • \\ Bevin Brush • Dick Jansen • Donald Dry • \\ George Brooks · David Chamberlain
}

Received: 18 July 2012

(C) Akadémiai Kiadó, Budapest, Hungary 2012

\begin{abstract}
Source term information is required for to reconstruct a device used in a dispersed radiological dispersal device. Simulating a radioactive environment to train and exercise sampling and sample characterization methods with suitable sample materials is a continued challenge. The Idaho National Laboratory has developed and permitted a radioactive response training range (RRTR), an 800 acre test range that is approved for open air dispersal of activated $\mathrm{KBr}$, for training first responders in the entry and exit from radioactively contaminated areas, and testing protocols for environmental sampling and field characterization. Members from the Department of Defense, Law Enforcement, and the Department of Energy participated in the first contamination exercise that was conducted at the RRTR in the July 2011. The range was contaminated using a short lived radioactive ${ }^{82} \mathrm{Br}$ isotope (activated $\mathrm{KBr}$ ). Soil samples contaminated with $\mathrm{KBr}$ (dispersed as a solution) and glass particles containing activated potassium bromide that emulated dispersed radioactive materials (such as ceramic-based sealed source materials) were collected to assess environmental sampling and characterization techniques. This presentation summarizes the performance of a radioactive materials surrogate for use as a training aide for nuclear forensics.
\end{abstract}

K. Carney $(\square) \cdot$ M. Finck · C. McGrath · B. Brush · D. Jansen Idaho National Laboratory, P.O. Box 1625, Idaho Falls, ID 83415, USA

e-mail: kevin.carney@inl.gov

D. Dry · G. Brooks

Los Alamos National Laboratory, Los Alamos, NM 87545, USA

D. Chamberlain

Argonne National Laboratory, 9700 South Cass Avenue, Lemont, IL 60439, USA
Keywords Nuclear forensics - Neutron activation · Sol-gel glass $\cdot$ Radioactive dispersal device (RDD) surrogate

Information about the material source term of a detonated radiological dispersal device (RDD) is required to reconstruct the device in order to determine its origin, potential legitimate use and possibly identifying the point of loss of control. An important part of the reconstruction effort is to collect samples and data that provide information about the source or device. Doing this requires the development of suitable collection techniques with known sampling efficiencies in order to accurately estimate the material source term. Simulating a radioactive environment with suitable surrogate materials to test sampling and characterization methods is a challenge.

To date, most RDD training and exercise venues have used ${ }^{99} \mathrm{Mo}$ or ${ }^{67} \mathrm{Ga}$ as a source of short lived radionuclides. These isotopes have limited applicability as radioactive surrogates because they cannot be used in solid form, and thus cannot adequately emulate exploded, dispersed solid material for sampling. Liquids are absorbed into soils and porous surfaces that prohibit accurate sampling of solely the source material. INL has developed radioactive surrogate materials for salt and glass/ceramic forms of radioactive source materials using neutron activated potassium bromide $(\mathrm{KBr})$. This paper summarizes the performance of the radioactive materials surrogate for use as a training aide for nuclear forensics.

\section{Introduction}

Field sampling is an important aspect of reconstructing a detonated radioactive dispersal device (RDD) to determine the initial material activity and the number of sources and 
Fig. 1 Photograph (left) and micrograph (right) of the $25 \%$ by mass $\mathrm{KBr}$ containing sol-gel
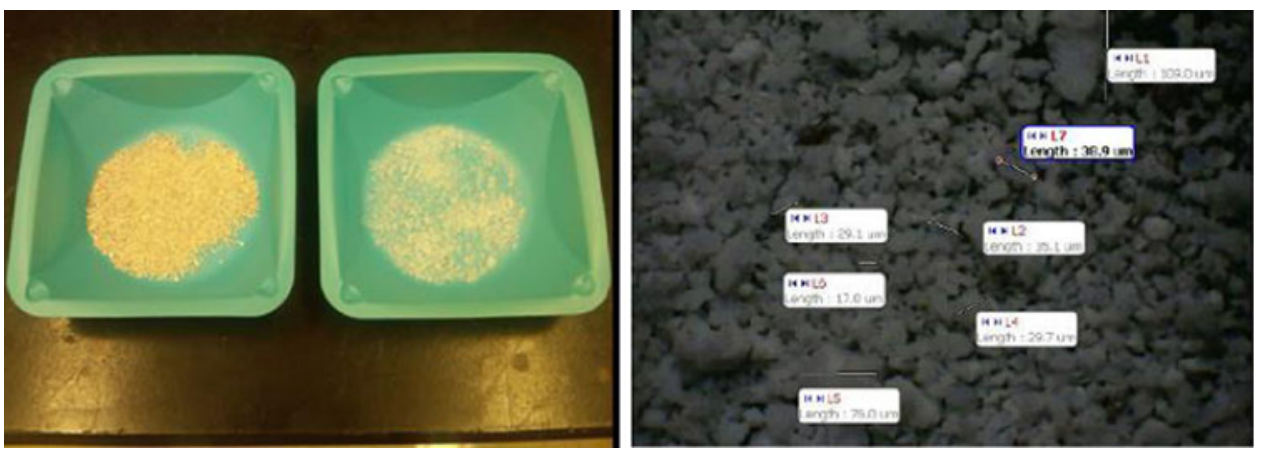

Table 1 Calculated isotope activities (Ci) at various cooling times after discharge for $1 \mathrm{~g} \mathrm{KBr}$ irradiated for $1 \mathrm{~h}$

\begin{tabular}{lllllllllll}
\hline Decay (curies) & & & & & & & & \\
\hline
\end{tabular}

types that hypothetically were used in an RDD event. Of particular importance to the forensics community are ${ }^{137} \mathrm{Cs}$ and ${ }^{90} \mathrm{Sr}$ sources. The chemical forms of these isotopes are either pressed salt pellets $(\mathrm{CsCl})$, glass silicates such as cesium or strontium silicates $\left(\mathrm{Cs}_{2} \mathrm{SiO}_{3}, \mathrm{SrSiO}_{3}\right)$ or ceramics such as cesium pollucite $\left(\mathrm{Cs}_{2} \mathrm{Al}_{2} \mathrm{Si}_{4} \mathrm{O}_{12} \cdot 12 \mathrm{H}_{2} \mathrm{O}\right)$ or strontium titanate $\left(\mathrm{SrTiO}_{3}\right)$. INL has developed radioactive surrogate materials for salt and glass/ceramic forms of radioactive source materials using neutron activated $\mathrm{KBr}$. The $\mathrm{KBr}$ has similar properties (i.e. melting point, structure) to $\mathrm{CsCl}$ and has also been incorporated into high purity sol-gel glasses to simulate Cs silicate and ceramic forms. $\mathrm{KBr}$ has similar crystal and physical properties to $\mathrm{CsCl}$ [1]. Each compound is found as a cubic lattice with similar heats of formation $\left(\Delta H_{\mathrm{f}}=-103.5\right.$ and $\left.-93.7 \mathrm{kcal} \mathrm{mol}^{-1}\right)$. The melting point and boiling points of $\mathrm{KBr}$ are 1,007 and 1,708 $\mathrm{K}$, respectively; the melting and boiling points of $\mathrm{CsCl}$ are 918 and 1,563 $\mathrm{K}$, respectively. Both compounds are highly soluble in water. Hence, $\mathrm{KBr}$ should be a good surrogate for $\mathrm{CsCl}$ for a variety of dispersion mechanisms (i.e. spray or explosion) and thus should provide realistic dispersions for training.

With respect to the glass matrix, it is synthesized using a sol-gel technique that can be readily doped with upwards of $25 \% \mathrm{KBr}$ by mass. The glasses are high purity which is beneficial for irradiation to avoid unwanted activation products. The particle size can be varied from micron up to millimeters in size and the density is similar to other glasses used in radioactive sources.

Potassium has three natural occurring isotopes, ${ }^{39} \mathrm{~K}$ $(93.3 \%),{ }^{40} \mathrm{~K}(0.012 \%)$ and ${ }^{41} \mathrm{~K}(6.73 \%)$. The primary radioactive potassium isotope formed is ${ }^{42} \mathrm{~K}\left(T_{1 / 2}=\right.$ $12.4 \mathrm{~h}$ ) that decays to stable ${ }^{42} \mathrm{Ca}$ by beta emission. The thermal capture cross section of ${ }^{41} \mathrm{~K}$ is 1.5 barns [2]. The 
Table 2 Sample masses and calculated ${ }^{82} \mathrm{Br}$ activities at sample collection times

\begin{tabular}{lllll}
\hline $\begin{array}{l}\text { Irradiation } \\
\text { sample }\end{array}$ & $\begin{array}{l}\text { Irradiation } \\
\text { rabbit }\end{array}$ & $\begin{array}{l}\text { Sample } \\
\text { mass }\end{array}$ & $\begin{array}{l}\text { Estimated } \\
82 \mathrm{Br} \text { activity } \\
(\mathrm{MBq}) \text { decay } \\
\text { corrected to } \\
13: 007 / 25 /\end{array}$ & $\begin{array}{l}\text { Estimated } \\
{ }^{82} \mathrm{Br} \text { activity } \\
(\mathrm{MBq}) \text { decay } \\
\text { corrected to } \\
13: 007 / 26 / \\
2011\end{array}$ \\
\hline 1 & & & 2011 \\
2 & 1 & 3.495 & 31 & 20 \\
3 & 1 & 3.616 & 32 & 20 \\
4 & 2 & 2.153 & 34 & 22 \\
5 & 2 & 2.097 & 33 & 21 \\
6 & 3 & 0.8787 & 20 & 13 \\
7 & 3 & 0.9584 & 22 & 14 \\
8 & 3 & 0.9663 & 22 & 14 \\
9 & 4 & 0.983 & 26 & 16 \\
10 & 4 & 1.024 & 27 & 17 \\
\hline
\end{tabular}

Table 3 Measured sample dose rates and activities ${ }^{82} \mathrm{Br}$ from collections

\begin{tabular}{lll}
\hline $\begin{array}{l}\text { Field } \\
\text { collection sample }\end{array}$ & $\begin{array}{l}\text { Sample dose rate } \\
(\mathrm{mRem} / \mathrm{h} @ 5 \mathrm{~cm})\end{array}$ & $\begin{array}{l}\text { Measured sample } \\
\text { activity }(\mathrm{MBq})\end{array}$ \\
\hline 13 & 15 & 1.4 \\
14 & 40 & 2.3 \\
15 & 60 & 3.0 \\
16 & 50 & 2.0 \\
17 & 10 & 1.0 \\
18 & 60 & 2.7 \\
\hline
\end{tabular}

anthropogenic production of ${ }^{40} \mathrm{~K}$ is insignificant relative to the natural quantity of ${ }^{40} \mathrm{~K}$ found in the salt. Bromine has two naturally occurring isotopes ${ }^{79} \mathrm{Br}(50.7 \%)$ and ${ }^{81} \mathrm{Br}$ $(49.3 \%)$ that activate by $(n, \gamma)$ reactions to form ${ }^{80} \mathrm{Br}\left(T_{1 /}\right.$ $\left.{ }_{2}=17 \mathrm{~min}\right)$ and ${ }^{82} \mathrm{Br}\left(T_{1 / 2}=35.3 \mathrm{~h}\right)$ [3]. Each $\mathrm{Br}$ isotope decays to stable $\mathrm{Kr}$ isotopes. After $72 \mathrm{~h}$ from end of irradiation, ${ }^{82} \mathrm{Br}$ is the primary radionuclide contributing to gamma emission and radiation dose rate; it has major gamma emission rays at $776 \mathrm{keV}(83.5 \%)$ and $554 \mathrm{keV}$ (70.8\%) [4]. From the perspective of a short lived training stimulant, the irradiated $\mathrm{KBr}$ has no long-lived detrimental radioisotope; traces of Se are formed but in insignificant quantities, the calcium and krypton decay produces stable isotopes.

INL has built the radioactive response test range (RRTR), an 800 acre training site that is permitted to release $37 \mathrm{GBq}$ of irradiated $\mathrm{KBr}$ activation products. An exercise was conducted that used irradiated glass containing $25 \%$ by mass $\mathrm{KBr}$ as a radioactive sample surrogate to estimate sampling efficiency. This paper presents the result of the use of the surrogate $\mathrm{KBr}$ glasses obtained from a field collection exercise.

\section{Experimental}

Preparation of glasses using sol-gel synthesis

Potassium bromide containing glasses were prepared using a sol-gel synthesis [5] in $50 \mathrm{~g}$ batches that result in a variety of particle sizes ranging from micron to millimeter in size. The silica matrix was formed by the acidic hydrolysis of tetraethyl orthosilicate (Sigma $99.999 \%$ trace metals basis) for $4 \mathrm{~h}$ at a temperature of less than 313 K. High purity (99.999\%) "Spectrograde" $\mathrm{KBr}$ powder (Crystal Labs) was dissolved into the mixture. The silica was cross linked by the addition of high purity $\mathrm{KOH}$ (Sigma $99.99 \%$ semiconductor grade) to adjust the $\mathrm{pH}$ of the solution to 8.6. The solidified silicate was calcined for $3 \mathrm{~h}$ at $873 \mathrm{~K}$ resulting in a dense glass particulate; at temperatures above $873 \mathrm{~K}$ vaporization and loss of the bromine was observed. A photograph of the batch produced sol-gel silicate glass is shown in Fig. 1. KBr was incorporated into separate glass batches at concentration levels of $25 \%$ by mass.

Neutron irradiation and sample preparation

ORIGEN [6] calculations were used to estimate the sample activity. For the purposes of this calculation, $1 \mathrm{~g} \mathrm{KBr}$ was modeled in a thermal neutron flux of $2.5 \times$ $10^{12} \mathrm{n} \mathrm{cm}^{-2} \mathrm{~s}^{-1}$ for an irradiation time of $1 \mathrm{~h}$. The total activity of the activated $\mathrm{KBr}$ at discharge was estimated to be $0.22 \mathrm{GBq} \mathrm{g}^{-1} \mathrm{~h}^{-1}$ and decayed accordingly for a variety of cooling times. The resulting activity calculated at discharge out to 4 weeks is provided in Table 1 . The activities reported in Table 1 are reported in Curies, the output of ORIGEN code.

Polyethylene containers were pre-cleaned with high purity 2-propanol then rinsed with 18 Mohm water. Ten glass samples containing $\mathrm{KBr}$ at $25 \%$ by mass ranging from 1 to $4 \mathrm{~g}$ were loaded into polyethylene containers and irradiated in aluminum rabbits for $1 \mathrm{~h}$. Gold wires were irradiated to confirm the reactor flux. Sample sizes, irradiation times and cooling times were adjusted in order to irradiate sufficient samples for a minimum of ten sample collection operations. The sample masses and calculated activity of the samples at the time of shipment from the irradiation facility is provided in Table 2. The time of shipment was used because the samples were irradiated on different days due to handling limitations in the reactor and the time of shipment is within a few hours of deposition and the onset of the experiment. The estimated activity 
Fig. $2 \mathrm{NaI}$ spectrum irradiated $\mathrm{KBr}$ containing sol-gel glass

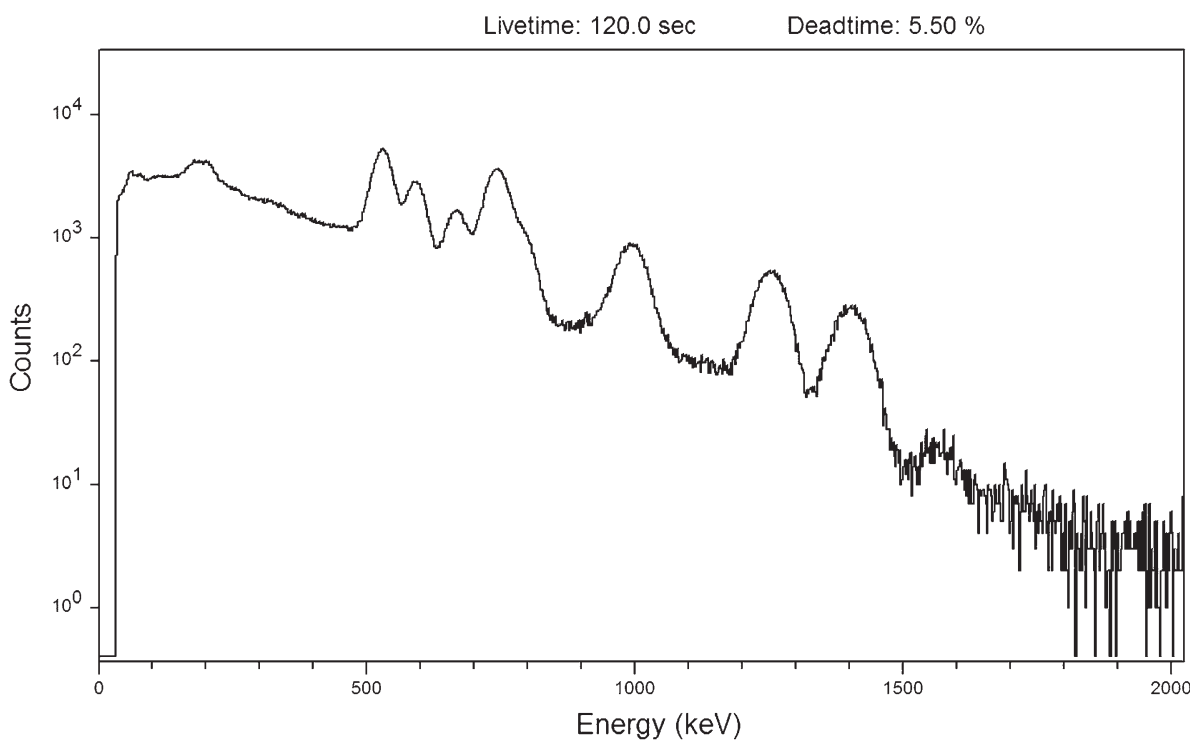

ranged between 20 and $34 \mathrm{MBq}$. Gamma spectrometry results confirmed the purity of the glass after activation and the activity of the ${ }^{82} \mathrm{Br}$. The measured activity matched the calculated activity within $10 \%$.

Field sample set-up

Sampling platforms were constructed from $4 \times 4 \mathrm{ft}$ wood pallets that were coated with 1 inch of asphalt or concrete. The pallets were placed in $10 \times 12 \mathrm{ft}$ canvas tents equipped with snap in canvas floors. This provided a containment that was required to contain the irradiated silicate glass and permitted unhindered entry. The irradiated glass particulate was deposited manually onto the sampling surfaces. Samples were collected manually or using portable vacuum samplers. Ten sampling stations were established in the RRTR gravel pit. Fireplace ash, indigenous soil and gravel were sprinkled on the surfaces with the $\mathrm{KBr}$ to provide a matrix that would emulate ash from fires and debris from collapsed structures. The dose rates for samples measured at contact ( 2 inches) deposited at the sampling stations is provided in Table 3 . The radiation levels of the sol-gel samples at use did not present a handling hazard and provided a measurable dose rate at distances out to $1 \mathrm{~m}$. The $35 \mathrm{~h}$ half-life of the ${ }^{82} \mathrm{~B}$ provided sufficient activity for the 3 days use.

Samples numbered 13, 14 and 22 were collected at stations where $1 \mathrm{~g}$ of irradiated $\mathrm{KBr}$ doped glass was deposited; samples 17, 18, 19, and 20 were collected at stations that contained approximately $3.5 \mathrm{~g}$ of the irradiated $\mathrm{KBr}$ doped glass. Field processing consisted of measuring the dose rates at contact $(5 \mathrm{~cm})$ from each sample and obtaining the sample spectrum and activity with a $\mathrm{NaI}$ or HpGe detector. One sample, number 13, was processed by sieving onto three sieves with mesh sizes greater than $2 \mathrm{~mm}$, greater than 850 microns, and greater than 500 microns were used to process the sample. This process was evaluated to provide a sample that had minimal environmental contamination (i.e. dirt) that confounds the determination of the age since material purification. Sample activities were measured using a sodium iodide detector.

\section{Results and discussion}

Several processes were evaluated in this process. Adequate samples with sufficient activities were collected and processed. An important step was sample sieving. For this process, the glass was robust and could survive sample sieving that removed as much soil and ash as possible. The greater than $850 \mu \mathrm{m}$ sieve contained $58 \%$ of the sample mass and $65 \%$ of the sample activity. The greater than $500 \mu \mathrm{m}$ sieve contained $25 \%$ of the sample mass and $29 \%$ of the sample activity. The less than $850 \mu \mathrm{m}$ sieve fraction contained $17 \%$ of the sample mass and only $7 \%$ of the sample activity. This indicates a significant fraction of the ash and soil could be removed by sieving for this particle size distribution. It is to be determined if sample sieving could be beneficial to an explosively dispersed RDD for salt, glass or ceramic materials.

A second important test was the ability of field teams to correctly identify and assay the samples using gamma spectrometry. A screen capture of a representative spectrum obtained from field measurements of the irradiated sol-gel $\mathrm{KBr}$ containing glass obtained using a NaI detector is provided in Fig. 2. Analogously, a screen capture of a higher resolution gamma spectrum obtained with an Ortec Detective high purity germanium detector in the field is 
Fig. 3 HpGe spectrum irradiated $\mathrm{KBr}$ containing sol-gel glass

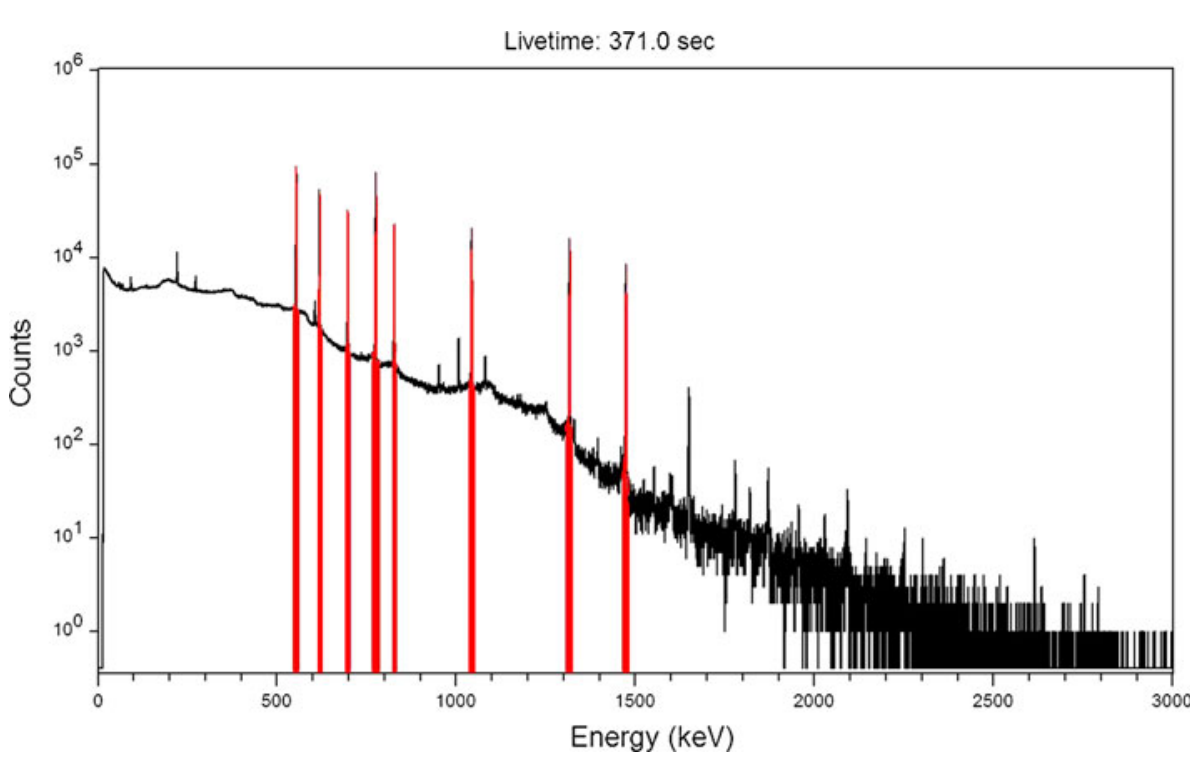

shown in Fig. 3. The ${ }^{82} \mathrm{Br}$ spectrum provides an adequate number of gamma emission lines for training in peak and species identification and quantification. The activity in each sample was determined using spectra obtained from collected samples. The total ${ }^{82} \mathrm{Br}$ activity in the samples ranged from 0.96 to $4.1 \mathrm{MBq}$. The manual dispersion process for depositing the glass samples resulted in a heterogeneous distribution of the samples on the sampling platforms. This made the direct assessment of the sampling efficiency difficult. Collectively, the measured sample activities were approximately $1 / 10-1 / 5$ th of the activity placed on the sample pods based on the deposited and measured sample activities. This represents 10-20\% of the activity deposited for collection. This is the first attempt to assess the sample collection efficiency using radioactive samples. To obtain a better estimate, the homogeneity of the sample dispersion needs to be improved to more accurately assess sampling efficiency.

\section{Conclusions}

Irradiated samples of glass containing $25 \mathrm{wt} \% \mathrm{KBr}$ were used at INL's RRTR to test sample collection efficiency. The collection efficiency was estimated to range from 10 to $20 \%$. The glass samples provided a medium to test sample collection and measurement techniques. Activated $\mathrm{KBr}$ contained in glass particulate was dispersed to provide radioactive samples for collection. The samples provided a realistic medium for sample collection of controlled surfaces with in-field characterization.

Acknowledgments The authors acknowledge Mr. Sean Cunningham and Mr. Andrew Smolinski and the INL's neutron radiography Training Research Isotopes General Atomic (TRIGA) reactor staff for providing sample irradiations. Also recognized are the efforts of Mr. Marcos Jimenez, Mr. James Sommers, Dr. Jeffrey Giglio, and Dr. Jackie Fonnesbeck for vial cleaning and loading.

\section{References}

1. Lide DR (ed) (1990-1991) Handbook of chemistry and physics, 71 st edn. CRC Press Ltd., Boca Raton

2. Baum EM, Knox HD, Miller TR (2002) Nuclides and isotopes: chart of the nuclides, 16th edn. Knolls Atomic Power Laboratory, Schenectady

3. Datta J, Chowdhurry DP, Verma R, Reddy VA (2011) J Radioanal Nucl Chem. doi:10.1007/s10967-011-1549-1

4. Coleman ME, Glascock MD, Robertson JD (2011) J Radioanal Nucl Chem 287:935-941

5. Su et al (1990) Modification of US Patent 4,943,425

6. Gauld I, Hermann OW, Westfall RM (2009) Origen-S. ORNL/ TM-2005/39 version 6 vol II, sect F7. Oak Ridge National Laboratory, Oak Ridge 